\title{
Electrical tomography and TDEM prospection in the Chianciano thermal basin (Siena, Italy)
}

\author{
Giuseppe Pagano, Antonio Menghini and Stefano Floris \\ Studio di Tecnologie per la Geologia e l'Ambiente (S.Te.G.A.), Viterbo, Italy
}

\begin{abstract}
Chianciano thermal basin in Tuscany belongs to a great structure that extends, from San Casciano Bagni to Rapolano, orientated SSE-NNW. Several springs are located in this thermal field: Acqua Santa, Macerina, Casuccini and Sillene well. They are located close to the contact between the lower complex of the «Tuscan series» (Triassic limestones and dolomites) and Pliocene formations (sands and clayey sands, clays and silty clays). According to the groundwater flow scheme, the former formations represent the geothermal reservoir and, where they outcrop, the recharge areas. Thermalized fluids rise through direct faults, having an apennine orientation. In order to locate a new production well, electrical tomography and TDEM prospection were performed. Geophysical interpretation led to the construction of $1 \mathrm{D}$ imaged and 2D sections showing the main tectonic features. The different electrical behaviour of the hydrogeological units disclosed a fault located near the old Sillene well; this tectonic feature caused the uplifting of Triassic formations towards the north-east. A new production well was located close to the fault in the uplifted sector with excellent results as it captured the thermal aquifer at a depth of $30 \mathrm{~m}$ with a discharge up to 70 1/s.
\end{abstract}

Key words TDEM - transient electromagnetics electrical tomography - thermal waters - Chianciano Terme

\section{Introduction}

The thermal spa of Chianciano is one of the most popular in Italy. Its mineral waters have been utilized since the Etruscan age, as testified by the discovery, in 1868, of a temple of the 5th century B.C. (Angeli et al., 1990). The increasing development of the thermal industry and the demand for ever-growing supplies, led the company «Terme di Chianciano S.p.A.»,

Mailing address: Dr. Antonio Menghini, Studio di Tecnologie per la Geologia e l'Ambiente (S.Te.G.A.), Via Monte Bianco 5, 01100 Viterbo, Italy; e-mail: stega@ stega.it which manages the spa complex, to search for other sources. In 1998 the Society entrusted us to locate a new production well to increase groundwater supply.

Electrical tomography and TDEM prospection were performed to define a stratigraphic and a tectonic outline. The former method has been widely used in hydrogeological investigations, also in the case of complex geological structures (Griffiths and Barker, 1993; Dahlin, 1996; Abdul Nassir et al., 2000; Seaton and Burbey, 2000; Demanet et al., 2001). Electrical tomography has the great advantage of being suitable in difficult environmental conditions, like urban landscapes in the survey area.

TDEM prospection has also been frequently applied in hydrogeology (Fitterman and Stewart, 1986; Fitterman, 1987; Hoekstra and Blohm, 1990; McNeill, 1990; Taylor et al., 1992; Floris et al., 1995; Poulsen and Christensen, 1999; Sorensen et al., 2001). 
In this paper, we show how the combined use of these two geophysical methods is able to acquire detailed stratigraphic and tectonic informations, which are necessary to plan future interventions. Both the techniques permit independent estimation of the same parameter, the electrical resistivity, in the same depth range. Results were fully satisfactory, in spite of the presence of relatively high cultural noise.

\section{Geological and hydrogeological setting}

Chianciano spa (municipality of Siena) is located in Tuscany, Central Italy; it is part of a major thermal basin which extends from San Casciano Bagni to Rapolano, orientated SSE-
NNW (Fancelli and Nuti, 1975). The regional structural map in fig. 1 (Bossio et al., 1992) shows the presence of a series of Neogenic and Quaternary basins. They were formed during the Pliocene tensional tectonic phase, which caused the creation of wide depressions, filled with mainly argillaceous marine deposits. The tectonic outline is complicated by the previous compressional phase, which caused the overfold of the Mesozoic carbonatic terrains, with the separation occurring in the Triassic anhydritic formations (Lazzarotto, 1972).

The area of Chianciano is located at the passage between the structural high of Cetona Mountain and a Neogenic basin. These two tectonic units are separated by a faulting system (which may be an overthrust, according to some

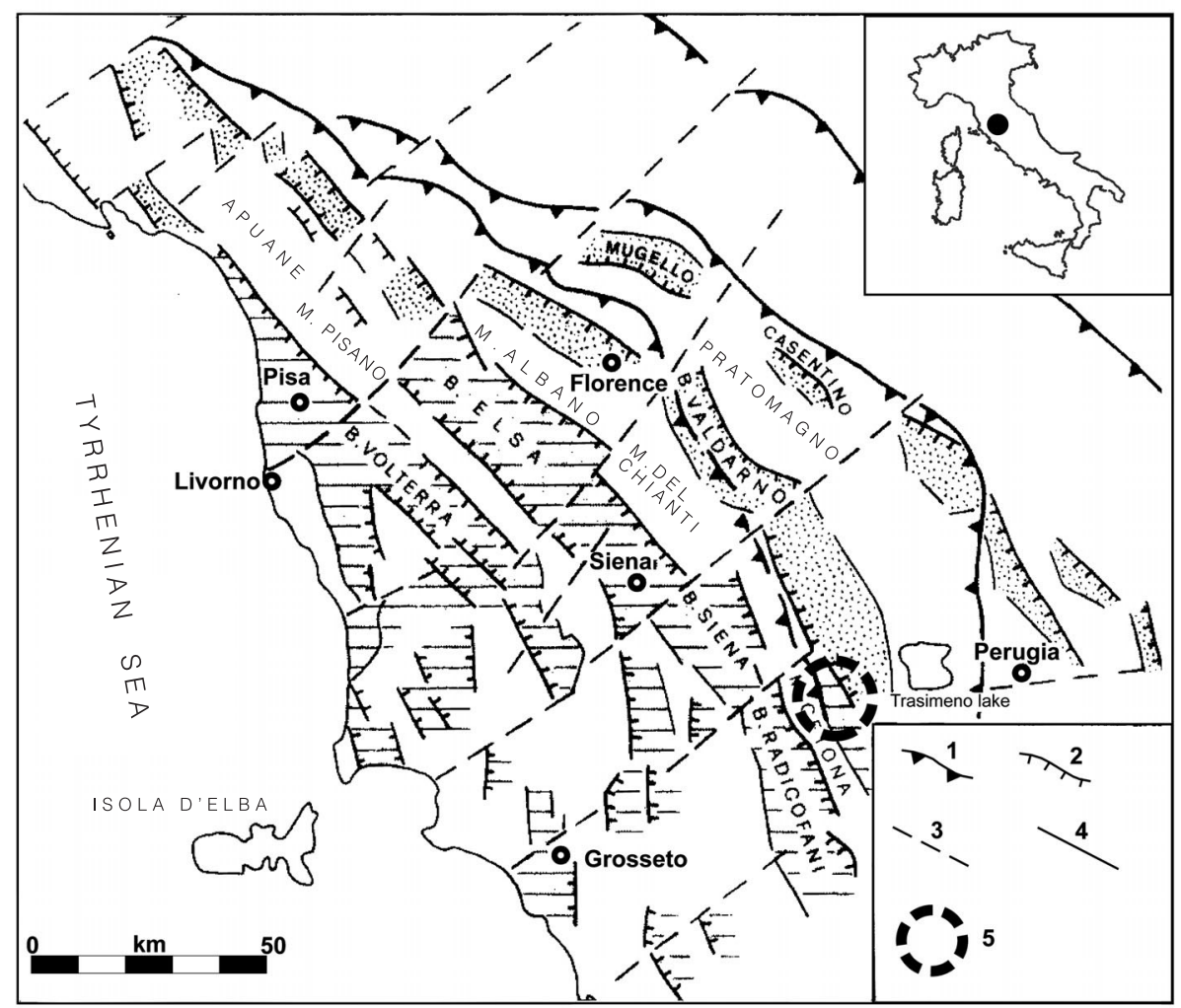

Fig. 1. Location of the main Neogenic and Quaternary basins (after Bossio et al., 1992, modified). Dashed areas show Mio-Pliocene basins; dotted areas show Plio-Pleistocene basins. $1=$ Main overthrust; $2=$ main faults at the edges of the basins; $3=$ transversal tectonic lines; $4=$ minor faults at the edges of the basins; $5=$ survey area. 


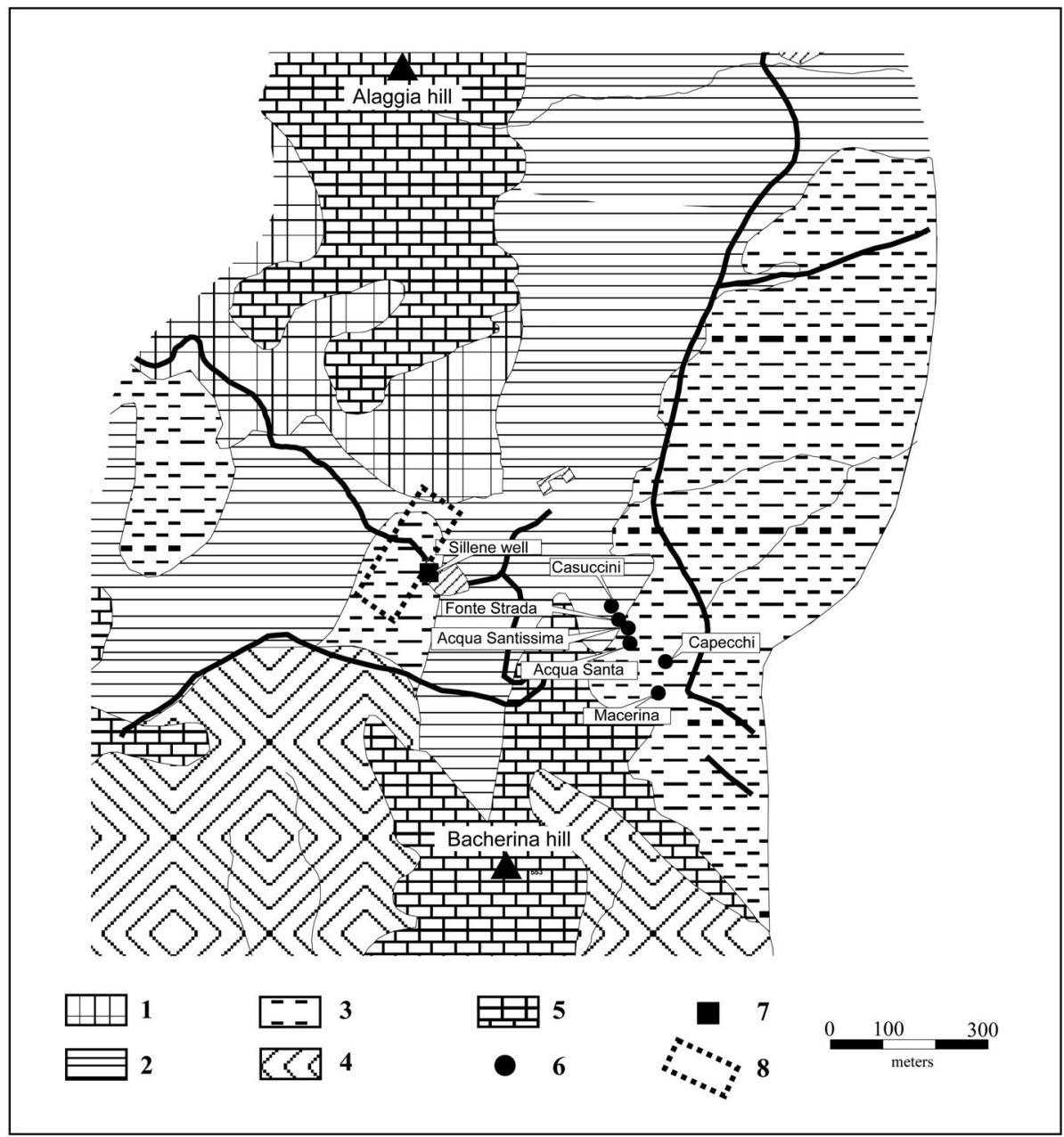

Fig. 2. Schematic geological map of the Chianciano thermal basin (after Compagnia Mediterranea di Prospezioni, 1973, modified). 1 = Recent alluvium; 2 = sands and clayey sands; 3 = clays and silty clays; 4 = clayey turbidites; $5=$ limestones and dolomites; $6=$ thermal springs; $7=$ Sillene well; $8=$ survey area.

authors), close to which the majority of the hot water springs are located.

The schematic geological map (fig. 2) is drawn from the hydrogeological and geophysical study performed by Compagnia Mediterranea di Prospezioni (1973). The majority of springs are located close to the area of contact between limestones and dolomites (Trias), and Pliocene formations (sands and clayey sands, clays and silty clays). The Triassic formations are related to the lower complex of the «Tuscan series» and outcrop as small isolated strips, on Bacherina Hill and Alaggia Hill, at an elevation ranging between 560 and $700 \mathrm{~m}$ a.s.1.

Sharp hydrogeological differences exist between the lower complex and the Pliocene formations, because the former is highly permeable by fissuring, whereas the latter has low permeabilty.

The groundwater flow scheme locates the recharge areas on the calcareous and anhydrite 


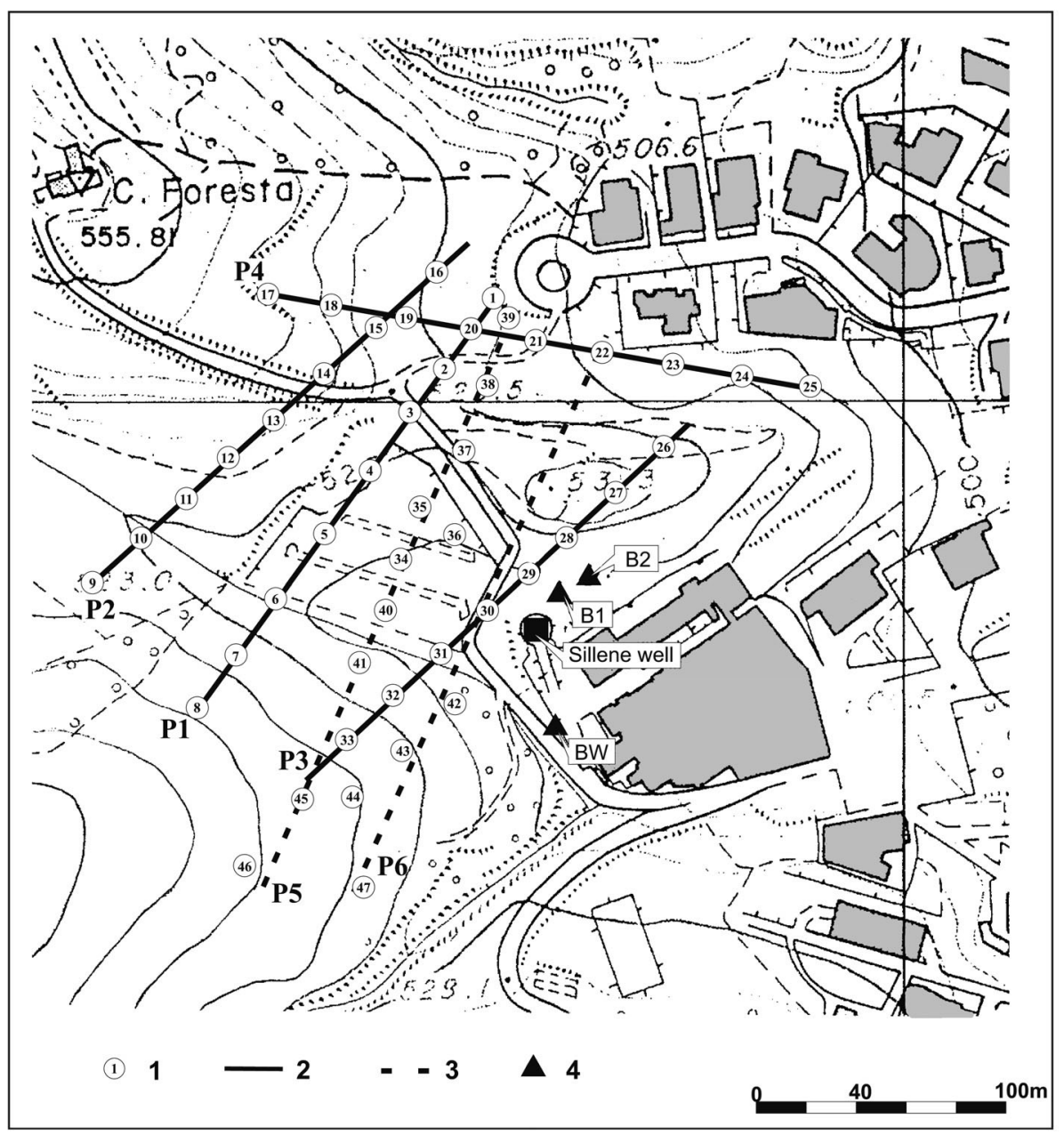

Fig. 3. Location map of geophysical prospections: $1=$ TEM sounding; $2=$ electrical and coincident electromagnetic profile; 3 = electromagnetic profile; 4 = borehole (BW = Benelli well; $\mathrm{B} 1=$ borehole $\mathrm{n} .1$; B2 = borehole $\mathrm{n} .2$ ).

outcrops, since chemical analyses referring to oxygen $\left(\delta \mathrm{O}^{18}\right)$ and hydrogen $(\delta \mathrm{D})$ isotopes (Fancelli and Nuti, 1975), show a mean elevation of infiltration of $800-900 \mathrm{~m}$ a.s.1., relating to Cetona Mountain relief (Palazzi, unpublished). Here meteoric waters infiltrate, recharging the geothermal reservoir. They may come into contact with highly thermalized fluids which rise through faults, producing waters with various chemical mixture. Generally the hot waters of the basin are sulphate-calcium, due to the leaching of the reservoir's rocks. The most important springs (Acqua Santa, Macerina and Casuccini) have a NW-SE (Apennine) alignment, showing a clear structural control.

On the contrary, Sillene, which has been captured by a well, is located to the west of the springs, far from evident faults. In 1991 a new well was drilled; it presented the following stratigraphic succession: from 0 to $9.3 \mathrm{~m}$ filling materials, from 9.3 to $11 \mathrm{~m}$ blue-grey clays, from 11 to $31 \mathrm{~m}$ alternated layers of massive and fis- 


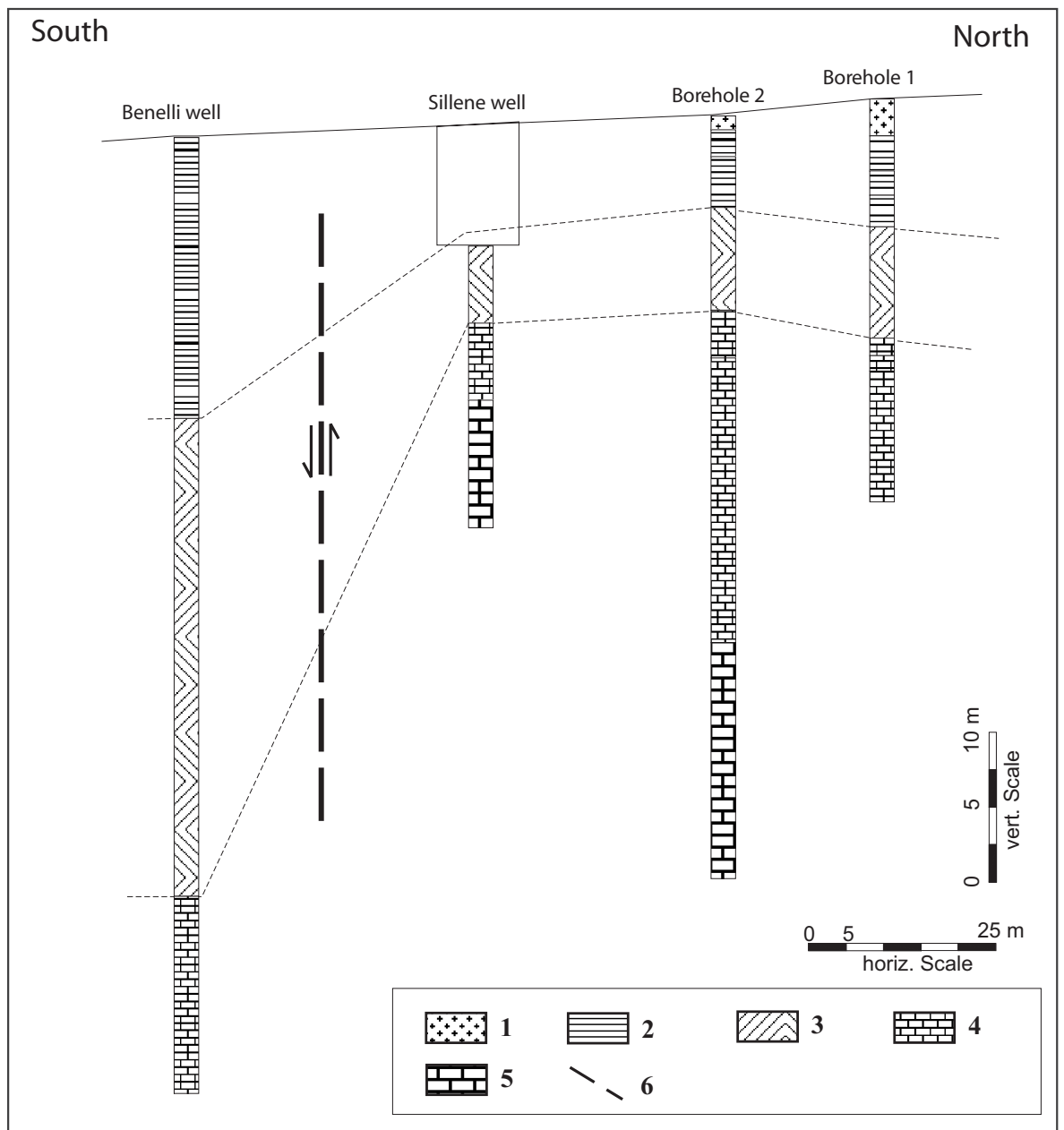

Fig. 4. Geological section: $1=$ fill; $2=$ sands and clayey sands; $3=$ clayey turbidites; $4=$ dolomitic sands; $5=$ «calcare cavernoso» breccias; $6=$ fault.

sured limestones, dolomitic sands and «calcare cavernoso» breccias. At the top of the limestones an artesian aquifer was captured.

Boreholes executed in the surrounding area, whose locations are shown in fig. 3 , show the presence of a sharp lithological passage, to the south of the Sillene well, probably due to a fault. The geological section (fig. 4) shows the sudden sinking of the top of the Dolomitic sands, which from a depth of about $11-16 \mathrm{~m}$ reaches $50 \mathrm{~m}$, in the Benelli well. Therefore the Sillene area seems to rest on a structural high. Sands and clayey sands outcrop on the sides of the Sillene well, while the layers at the top of the dolomitic sands consist of blue-grey clays and clayey turbidites.

\section{Methods of investigation}

The location of geophysical prospections is drawn in fig. 3. Electrical tomography prospection 
was performed by 4 profiles, using N-Digit PASI georesistivimeter; we adopted a Schlumberger array, electrode spacing of $4 \mathrm{~m}$ and 48 electrode cables. It was possible to investigate to a depth of 20-30 m. Inversion was executed by Res2dinv software, which uses the rapid inversion algorithm of Loke and Barker (1996), also taking into account topographic corrections. The results are presented as 2D sections, assuming constant resistivities in the third dimension perpendicular to the survey line.

Time Domain ElectroMagnetic (TDEM) prospection was performed by 47 soundings, mostly located along the same profiles as the electrical tomography prospection. Geonics Ltd equipment was used. TEM47 transmitter, highfrequency coil and a $2 \times 2 \mathrm{~m}, 9$ turns transmitting loop were used, for TEM soundings ranging from n. 1 to n. 33. The small size of the equipment allowed us to carry out the survey very quickly: all the soundings were performed in one day, by only two persons. TEM soundings ranging from n. 34 to $n$. 47 were executed by TEM57 transmitter, medium-frequency coil and loops of size ranging from $30 \times 30 \mathrm{~m}$ to $50 \times 50 \mathrm{~m}$, according to the available space. In every case a Protem receiver was used. Repetition frequency bands varied from $236.5 \mathrm{~Hz}$ (Ultra-High) to 6.25 $\mathrm{Hz}$ (Medium). The multi-turn loop obliged us to use the offset configuration, while for the larger loop a central location was adopted.

TDEM soundings were inverted by TemixGL software (by Interpex Ltd); use of Occam's smoothed inversion and a concatenating routine provided by WingLink software (by Geosystem s.r.l.) allowed us to obtain imaged sections, like tomographic ones. It is important to note that the single soundings were interpreted separately, so that the inversion is really 1D. 2D or 3D interpretation tools are not commercially available, due to complex modelling and inversion procedures. Usually $3 \mathrm{D}$ effects are considered separately (Goldman et al., 1994b) and are interpreted by forward modelling, which requires time-consuming techniques.

The 1D smooth modelling provided by Temix-GL estimates the absolute resistivity of a maximum of 19 thin layers, so that it discriminates small vertical variations. The model depths are logarithmically spaced and are generated from a minimum and maximum depth. A starting model is not necessary, so the inversion is completely automatic. Occam's inversion seeks to minimize the «roughness» of the model, to produce the smoothest model fitting the data.

Lateral resolution depends upon the spacing between TEM soundings, but also upon the size of the loop; in fact, according to Krivochieva and Chouteau (2001), 1D interpretation is suitable when the lateral variations of resistivity occur over distances larger than the size of the loop. From this point of view, the $2 \times 2 \mathrm{~m}$ multi-turn system should work better.

\section{Results and discussion}

The geophysical prospection defined of the stratigraphic outline of the survey area. In order to compare the results of the two methods, the ElectroMagnetic (EMP) and the Electrical Tomographic Profiles (ETP) will be shown together for each profile. Colour scale for the first ones was arranged in such a way that resistivity increases from blue to green tonalities. The palette used for the visualization of ETP shows blue colours for low resistivity, green for medium and red for high resistivity. It was deemed more suitable to use different palettes, because of the different range of resistivity collected by the two methods. TEM soundings measure systematically lower values than electrics due to the well-known effect of the way of propagation of the flowing currents (Fitterman et al., 1990): in stratified rocks, the resistivity measured perpendicular to bedding is higher than the resistivity in the bedding direction. TEM soundings induce horizontally flowing currents, like «smoke rings» (Nabighian, 1979), whereas electric soundings also cause a vertical flow, so transient system measures a lower value of resistivity in a horizontally stratified rock.

Furthermore, this common lowering in TDEM resistivities can be ascribed to the use of different inversion algorithms for the construction of the geophysical sections, as Occam's method generally attenuates the resistivity contrasts between layers.

Profile n. 1 (fig. 5) shows the presence of a sandy and clayey-sandy overburden, which is 


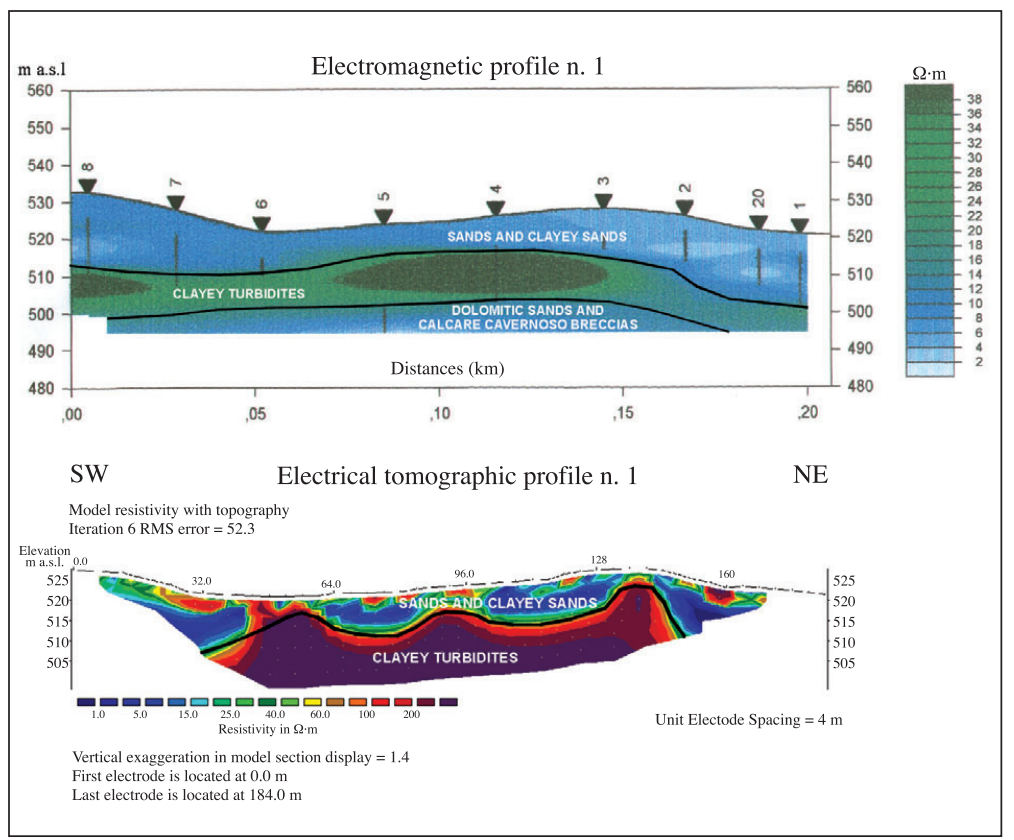

Fig. 5. Profile n. 1.

10-20 m thick. Obviously ETP is more apt to detect the thickness of this shallow formation, due to the poorer degree of resolution of the TDEM method as regards shallow targets. Resistivity values of EMP range from 6 to 12 $\Omega \cdot \mathrm{m}$, in accordance with the mean value of ETP. Some small lenses with high resistivity are interbedded into the overburden, but they were not resolved by TEM soundings, due to the previous problem. The lower lateral resolution of EMP must also be taken into account, because the spacing between TEM sounding is higher than that of the electrodes in ETP. Clayey turbidites are more resistive; they reach values of about 30-40 $\Omega \cdot \mathrm{m}$, in EMP, to 200-500 $\Omega \cdot \mathrm{m}$, in ETP.

Thanks to the greater depth of investigation, TEM soundings are able to detect a third layer, more conductive than the clayey turbidites, interpreted as dolomitic sands and «calcare cavernoso» breccias and lying at a depth of about 20-30 m. The striking conductive behaviour $(<10 \Omega \cdot \mathrm{m})$ can be explained only by taking into account the effect of the thermal fluids: the salinity of spring waters, which in the Chianciano basin ranges from 2600 to $3470 \mathrm{mg} / \mathrm{l}$, produces a strong decrease of rock resistivity, as reported by several authors (McNeill, 1980; Barker, 1990; Hoekstra and Blohm, 1990; Goldman et al., 1994a).

Profile n. 2 (fig. 6) again shows differences on the evaluation of the overburden thickness, as inferred by EMP and ETP. Both methods detect a minor fault, which caused a displacement of about $10 \mathrm{~m}$ and the sinking of the northerneastern sector. ETP shows, in correspondence of the fault, a localized low of resistivity, with a nearly vertical shape. The higher depth of investigation of TDEM method (about 30-40 m) is evident, whereas ETP does not detect the third layer.

Profile n. 3 (fig. 7) crosses the Sillene well; here the contact between Clays and Dolomitic sands, occurring at a depth of $11 \mathrm{~m}$, is marked by a passage from relatively high $(20-30 \Omega \cdot \mathrm{m})$ to very low resistivities $(2 \Omega \cdot \mathrm{m})$. This conductive lens is also well recognized by ETP, which 


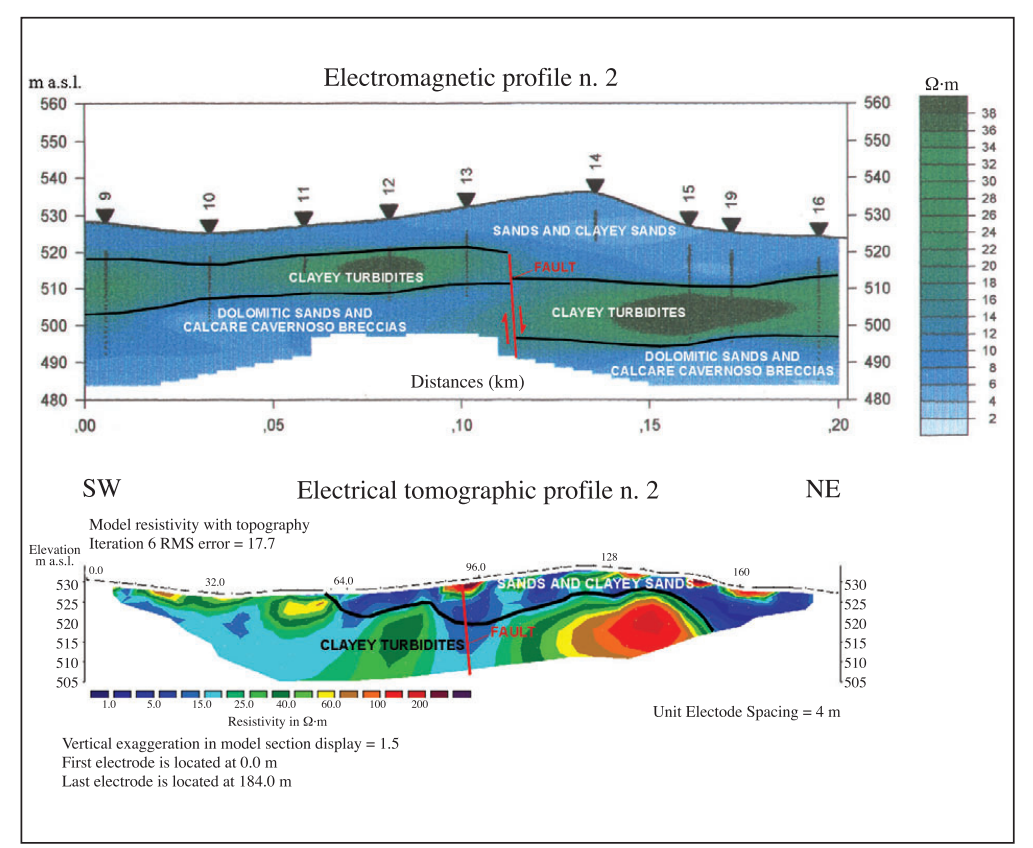

Fig. 6. Profile n. 2.

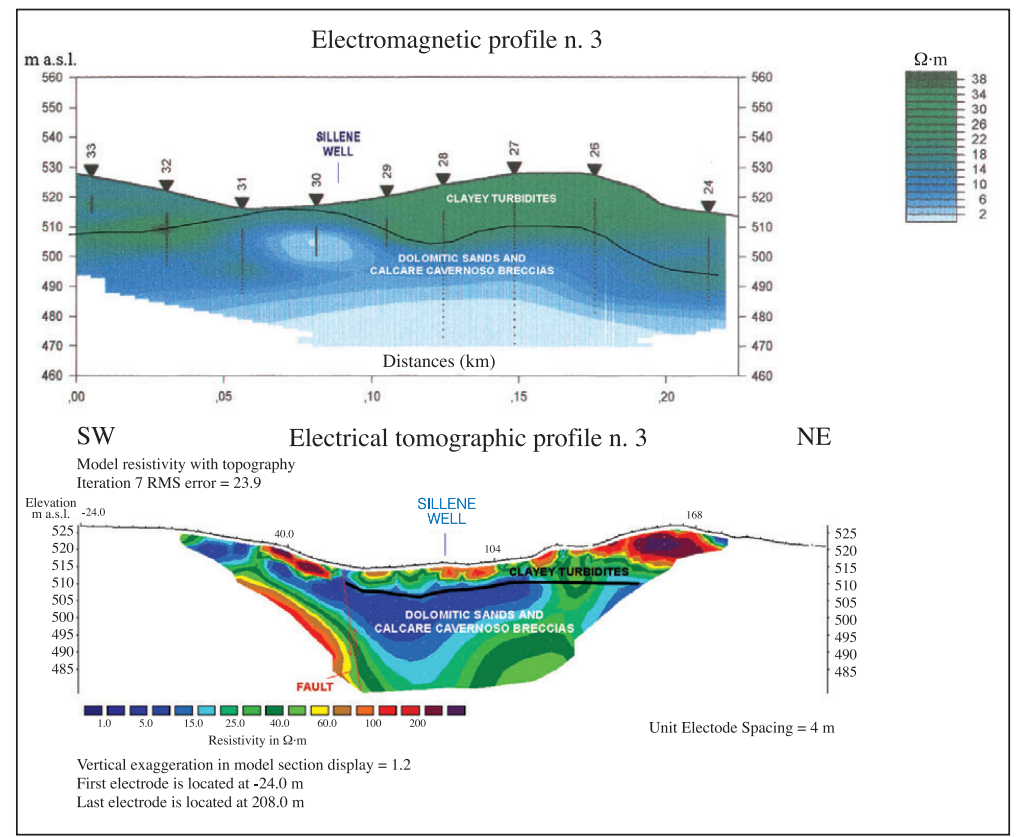

Fig. 7. Profile n. 3. 


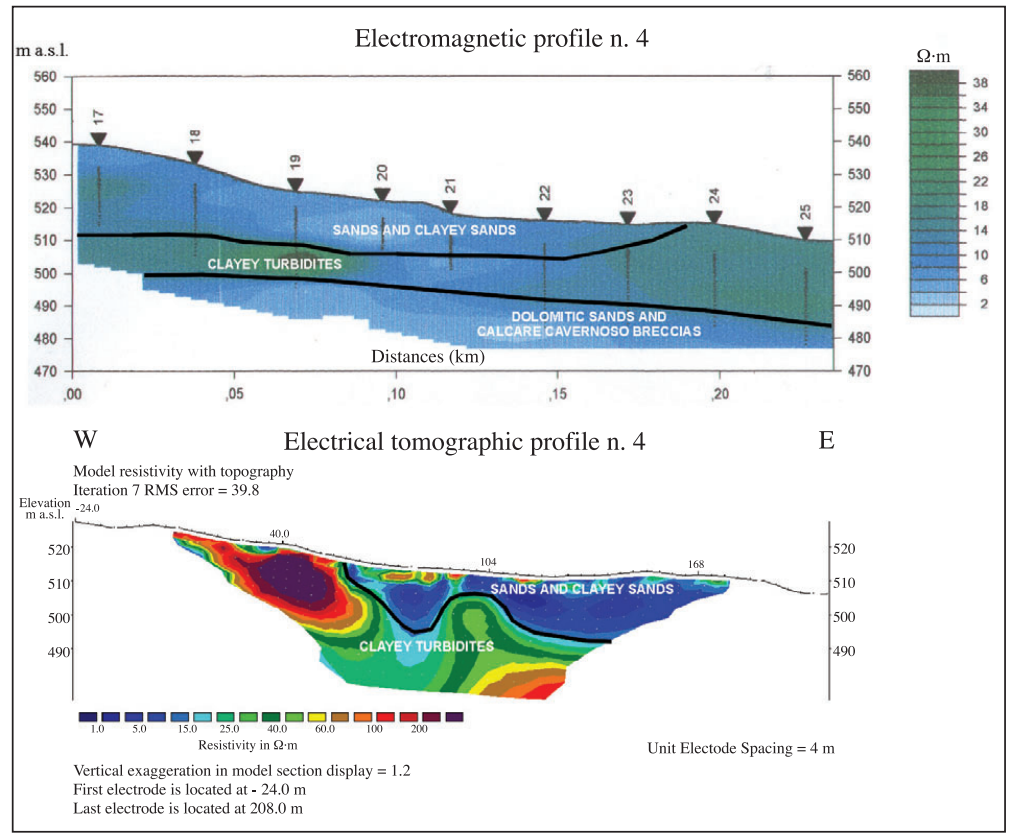

Fig. 8. Profile n. 4.

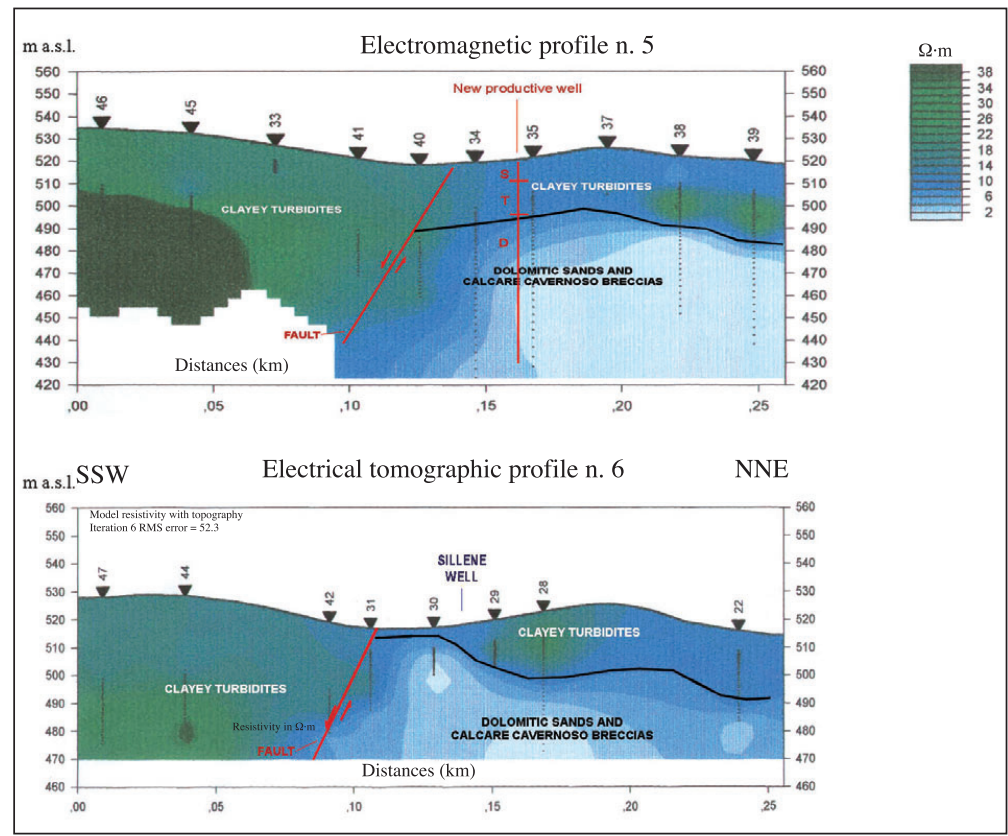

Fig. 9. Profiles n. 5 and 6. 
measures values of about $4-8 \Omega \cdot \mathrm{m}$. Unlike the previous tomographic profiles, the conductive Dolomitic sands are well resolved. On the southwestern side a fault is evidenced by ETP; EMP does not reveal this tectonic feature, probably because the variations of resistivity are too short and abrupt, although the $2 \times 2 \mathrm{~m}$ multi-turn loop was used in this profile.

Profile n. 4 (fig. 8) does not show important lithological variations or tectonic structures. Resistivity of clayey turbidites are again higher in $\operatorname{ETP}(30-70 \Omega \cdot \mathrm{m})$ than $\operatorname{EMP}(<40 \Omega \cdot \mathrm{m})$. The very resistive body, detected by ETP on the western margin, was not detected by TEM soundings, probably because it is too shallow.

Profiles n. 5 and n. 6 (fig. 9) have only electromagnetic data, but they are the most interesting because they show the presence of a fault which uplifted the Sillene area, the same as that detected by ETP n. 3 (fig. 7). ETP should provide a better «image», thanks to its higher lateral resolution and to the fact that it is the product of a real 2D inversion. On the contrary, EMP could be less sensitive to the horizontal passages, as it takes

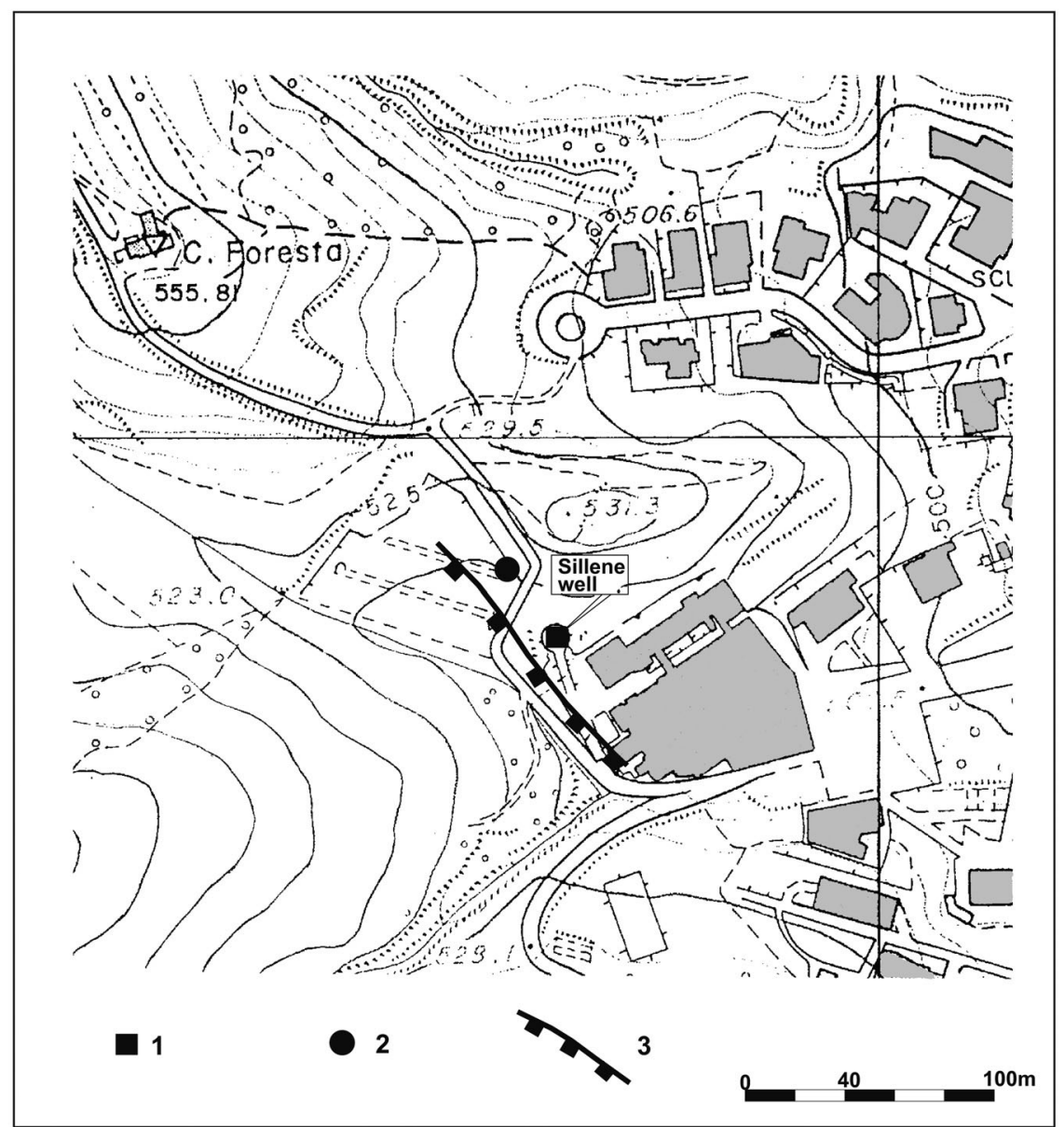

Fig. 10. Structural results from geophysical prospections. $1=$ Sillene well; $2=$ suggested location of the new well, and 3 = fault (rectangles show the lowered sector). 
into account TEM soundings with large loop size $(50 \times 50 \mathrm{~m})$

The higher depth of investigations of EMP n. 5 (up to $100 \mathrm{~m}$ ) must be emphasized. This result is particularly good, considering the high cultural noise and the presence of very conductive layers which slow down the transient.

Drawing the location of the main fault, which was detected by ETP n. 3, EMP n. 5 and EMP n. 6, an Apennine (NW-SE) orientation can be recognized (fig. 10). This orientation would suggest that this same fault produced the sinking of the Dolomitic sands in the Benelli well (fig. 4).

By geophysical prospection we distinguished schematically the following succession:

1) Sands and clayey sands (Middle Pliocene).

2) Clayey turbidites (Miocene).

3) Dolomitic sands and «calcare cavernoso» breccias (Trias).

The electrical behaviour of these formations is respectively conductive-resistive-conductive. In particular, sands and clayey sands are characterized by resistivity values of $10-20 \Omega \cdot \mathrm{m}$, clayey turbidites by values of $20-40 \Omega \cdot \mathrm{m}$, dolomitic sands and breccias by values of 1-10 $\Omega \cdot \mathrm{m}$. EMP and ETP show tectonic features that can be explained by a fault intersecting both clayey turbidites and dolomitic sands and breccias. These features are particularly evident near the Sillene well: here an uplifting of Mesozoic formations by an Apennine fault should be verified. In the lowered sector, which is located to the south-west of the Sillene well, the thermal fluids' flow is limited by the presence of impermeable turbidites. On the contrary, the thermal aquifer extends to the northeast of the fault, therefore the most promising point to drill a new production well can be accurately defined (fig. 10). This location assures the thermal aquifer can be reached at a shallow depth. The presence of the buildings connected with the spa complex made necessary it to move towards north-west, as well as remaining in the uplifted sector.

\section{Conclusions}

The combined use of electrical tomography and TDEM prospection defined the stratigraphic and tectonic outline of the area. The strong resistivity contrast between the hydrogeological units, made it possible to resolve the main fault that feeds the old Sillene well, allowing the rise of thermalized waters. This tectonic feature caused the uplift of Mesozoic formations to the north-east of the investigation area. The drilling result was excellent: the production well captured the thermal aquifer at a depth of $30 \mathrm{~m}$; it has a discharge up to $70 \mathrm{l} / \mathrm{s}$ and has confirmed the stratigraphic features expected by geophysical prospection: from 0 to $8 \mathrm{~m}$ sands, from 8 to $27 \mathrm{~m}$ clayey turbidites and from $27 \mathrm{~m}$ «calcare cavernoso» breccias. The location of the new well and its stratigraphic data were drawn on the EMP n. 5 (fig. 9): the correspondence between the top of the dolomitic sands and the conductive layer, representing the thermal aquifer is clear.

Notwithstanding the different way of inversion of the geophysical data, due to the lack of an univocal inversion algorithm which were suitable for both the methodologies, the results are encouraging. Different values of resistivity collected by the two techniques, are due to the different way of propagation of the flowing currents.

The advantages of using these two different kind of prospections are the objective comparison of the results, above all by a qualitative point of view, and a considerable power of resolution, both in lateral direction (by means of electrical tomography) and vertical direction (by means of TDEM prospection). Finally, in spite of the high cultural noise, it was possible to reach high depth of investigations, up to $100 \mathrm{~m}$.

\section{Acknowledgements}

The authors wish to thank «Terme di Chianciano S.p.A.» for the authorization to publish data, and the reviewers for their useful comments and suggestions.

\section{REFERENCES}

Abdul Nassir, S.S., M.H. LOKE, C.Y. LEE and M.N.M. NAWAWI (2000): Salt-water intrusion mapping by geoelectrical imaging surveys, Geophys. Prospect., 48, 647-661.

ANGELI, D., R. BETTI and A. FREGOLI (1990): Sorella Acqua- 
Chianciano le Terme la Comunità (Editori del Grifo).

BARKER, R.D. (1990): Investigation of groundwater salinity by geophysical methods, in Geotechnical and Environmental Geophysics, edited by S.H. WARD, Society of Exploration Geophysicists, Tulsa OK, vol. II, 201-211.

Bossio, A., R. Cerri, A. Costantini, A. Gandin, A. LAZZAROtTo, M. Magi, R. MAZZANTI, R. MAZZEI, M. SAGRI, G. SALVATORINI and F. SANDRELli (1992): I bacini distensivi neogenici e quaternari della Toscana, $76^{\circ}$ Adunanza Estiva Soc. Geol. Ital., Convegno SIMP, Firenze 21-23 Settembre 1992, Guida alle Escursioni, 199-277.

COMPAGNiA MEdITERRANEA DI ProsPEZIONI (1973): Studio Idrogeologico e Geofisico del Bacino di Chianciano.

DAHLIN, T. (1996): 2D resistivity surveying for environmental and engineering applications, First Break, 14, 275-283.

DEMANET, D., F. RENARDY, K. VANNESTE, D. JONGMANS, T. CAMELBEECK and M. MEghraOUI (2001): The use of geophysical prospecting for imaging active faults in the Roer Graben, Belgium, Geophysics, 66, 78-89.

FANCELLI, R. and S. NUTI (1975): Studio sulle acque termali e minerali della parte orientale della Provincia di Siena, Boll. Soc. Geol. Ital., 94, 135-155.

FITTERMAN, D.V. (1987): Examples of transient sounding for ground water exploration in sedimentary aquifers. Ground Water, 25, 685-692.

FitTerman, D.V. and M.T. STEWART (1986): Transient electromagnetic sounding for groundwater, Geophysics, 51, 995-1005.

FitTerman, D.V., F.C. FrischKNeCht, A.T. MAZZELla and W.L. ANDERSON (1990): Example of transient electromagnetic soundings in the presence of oil-field pipes, in Geotechnical and Environmental Geophysics, edited by S.H. WARD, Society of Exploration Geophysicists, Tulsa OK, vol. II, 79-88.

FLORIS, S., A. MENGHINI and G. PAGANO (1995): Transient electromagnetic soundings applied to hydrogeology: some case histories in Central Italy, in Proceedings of the 1st Meeting of the European Section of EEGS, Turin, 25-27 September 1995.

Goldman, M., A. Du Plooy and M. EcKard (1994a): On reducing ambiguity in the interpretation of transient electromagnetic sounding data, Geophys. Prospect., 42, 3-25.

Goldman, M., L. TABAROVSKy and M. RABINOVICH (1994b): On the influence of 3D structures on the interpretation of transient electromagnetic sounding data, Geophysics, 59, 889-901.

GRIFFITHS, D.H. and R.D. BARKER (1993): Two-dimensional resistivity. imaging and modelling in areas of complex geology, J. Appl. Geophys., 29, 211-226.

HoEKSTRA, P. and M.W. BlOHM (1990): Case histories of Time-Domain Electromagnetic soundings in environmental geophysics, in Geotechnical and Environmental Geophysics, edited by S. H. WARD, Society of Exploration Geophysicists, Tulsa OK, vol. II, 1-15.

KrivochiEva, S. and M. CHOUTEAU (2001): Improvement in 1D TDEM interpretation by simultaneous inversion of data from two loop configurations, J. Environ. Eng. Geophys., 6 (1), 19-31.

LAzZARotTo, A. (1972): Caratteri strutturali dei nuclei mesozoici di Montalceto, Trequanda e Piazza di Siena (Prov. di Siena), Atti Soc. Toscana Sci. Nat. Mem., Ser. A, 79, 251-256.

LOKE, M.H. and R.D. BARKER (1996): Rapid least-squares inversion of apparent resistivity pseudosection using a quasi-Newton method, Geophys. Prospect., 44, 131-152.

MCNEILL, J.D. (1980): Electrical conductivity of soils and rocks, Technical Note TN-5 (Geonics Limited, Mississauga, Canada), pp. 22.

MCNEILL, J.D. (1990): Use of electromagnetic methods for groundwater studies, in Geotechnical and Environmental Geophysics, edited by S.H. WARD, Society of Exploration Geophysicists, Tulsa OK, vol. I, 191-218.

NABIGHIAN, M.N. (1979): Quasi-static transient response of a conducting half-space: an approximate representation, Geophysics, 44, 1700-1705.

Poulsen, L.H. and N.B. Christensen (1999): Hydrogeophysical mapping with the transient electromagnetic sounding method, Eur. J. Environ. Eng. Geophys., 3, 201-220.

SeAton, W.J. and T.J. BuRbey (2000): Aquifer characterization in the Blue Ridge Physiographic Province using resistivity profiling and borehole geophysics: geologic analysis, J. Environ. Eng. Geophys., 5 (3), 45-58.

Sorensen, K.I., F. EFFERso and E. Auken (2001): A hydrogeophysical investigation of the island of Drejo, Eur. J. Environ. Eng. Geophys., 6, 109-124.

TAYLOR, K., M. WIDMER and M. CHESLEY (1992): Use of transient electromagnetics to define local hydrogeology in an arid alluvial environment, Geophysics, 57, 343-352. 